\title{
REFLECTIONS ON THE SIGNIFICANCE OF THE RELATIONSHIP BETWEEN MIND AND BODY IN MEDICINE
}

\author{
Boey CCM \\ Department of Paediatrics, Faculty of Medicine, University of Malaya, Kuala Lumpur, Malaysia.
}

\begin{abstract}
:
In the last three centuries, medicine has focused predominantly on the physical body as the source of disease, placing very little importance on the mind. However, the significance of mind-body interactions in medicine is now increasingly being recognised. True health must include both the physical body and the mind. This article traces our concepts of the relationship between mind and body since primitive times and explores its relevance to the maintenance of health. (JUMMEC 2010; 13(1): 3-11)
\end{abstract}

KEYWORDS: mind-body interaction

\section{Introduction}

For centuries, scientific thinking had been based on the concept of the separation of body and mind. 'Body' refers to all matter and physical phenomena, including the human body. 'Mind' refers to the unseen, spiritual, psychological aspects of life, including reason, intellect, memory, attention, will and emotion. It is the aspect of a person that enables the person to be aware of the world, to think and to feel.

Rene Descartes, the seventeenth-century French philosopher and mathematician, drew a strict distinction between mind and body. Descartes' mindbody dualism became the foundation of Western thought for many years and contributed to the separation of theology and science, of materialism and spiritualism, of body and mind. It supported the distinction in medical science between physical phenomena or diseases and those of a mental or emotional nature. To Descartes, the human body was a machine reducible to elementary parts and systems. While the idea of mind-body separation still remains strong to this day, the distinction has begun to fade as science and medicine make new discoveries.

\section{A historical overview of our understanding of mind-body interaction}

In primitive society $(10000 \mathrm{BC})$, disease was thought to be primarily caused by spiritual powers and, therefore, could be treated only by spiritual means. The evil spirit entering the human being had to be liberated through exorcism and similar means. The emphasis was almost exclusively on the spirit and there was very little consideration of the physical body. In some societies, even today, there is a dangerous lack of respect for medical science and an excessive reliance on superstition.

In the ancient civilizations such as the BabylonianAssyrian Civilizations (2500-500BC), medicine was often dominated by religion. Many Egyptian beliefs were based on myths and legends. However, there is evidence that in ancient Egypt, interest in human anatomy started to increase and there existed people who were referred to as physicians.

With time, a more holistic approach was adopted. There was more interest in the scientific study of the physiology of the human body, in addition to the psychological and spiritual aspects of life. The ancient Greek physician, Hippocrates, thought to have lived around $460 B C$ to $370 B C$ and often referred to as the 'father of medicine', wrote in his treatise, entitled Tradition in Medicine, that "no one can understand the science of medicine unless he knows what man is" (1), emphasizing that in order to cure the human

\section{Correspondence:}

Christopher Boey Chiong Meng

Department of Paediatrics

Faculty of Medicine, University of Malaya

50603 Kuala Lumpur, Malaysia

Email: ccmboey@um.edu.my 
body, it is necessary to have a knowledge of the whole of things. Over the following hundreds of years (100BC-AD400), various theories of the causation of disease were put forth, such as Galen's humoral theory that disease was caused by disturbance in the body fluids. This continued until the Middle and Dark Ages (around AD500-1450) when mysticism again dominated medicine. Sinning was thought to be the cause of mental and somatic illnesses.

During the Renaissance period (1500-1700), there was revival of interest in the natural sciences and their application to medicine as well as advances in anatomy, autopsy, microscopy and others. Around the 17th century, Descartes' concept of the 'dualism' or separation of the mind and body started to exert a strong influence on Western thought. In the 19th century, modern laboratory-based medicine, such as that practiced by Pasteur and Virchow, opened up a new era in medicine. From that time onwards, doctors began to feel that disease had its origin in disorders of the cell. The development of better microscopes enabled more details to be examined. Medicial practitioners became convinced that all disease must be associated with some kind of structural or functional cell change. Our understanding of the workings of the human body as well as of pathological processes progressed by leaps and bounds.

As time went on, however, the inter-relationship of the mind and the body was rejected as unscientific and matters related to the mind were relegated only to the realm of religion and philosophy. In the last three centuries of human existence, medicine has focused predominantly on the physical body as the source of disease, placing little importance on the mind. We have swung completely in the opposite direction from the days of our forefathers in primitive society where illness was thought to be entirely caused by spiritual powers. Although it has brought about many benefits, progress in the scientific understanding and treatment of disease is, unfortunately, in many instances also accompanied by a situation where the disease is treated, but not the whole patient. With its analytical and specialising approach, western medical science, though possessing great knowledge about pathological conditions, often regards illness and the diseased organ as separate from the human beings who are inflicted by the illness. This is an unfortunate consequence of the concept that mind and body are separate entities.

Professor Felix Unger, head of Cardiac Surgery at Salzburg State Hospital and President of the European Academy of Sciences and Arts, comments on the state of medical science today as follows: "Its strong inclination towards the natural sciences has caused medicine unintentionally to regard patients as peculiar cases describable in natural-scientific terms" (2).

\section{Psychological and physical illness - is there a real division?}

A large proportion of the training of doctors today is centred on the scientific diagnosis and treatment of diseases of the body. In doing so, we often categorise and compartmentalise. While this is important to enable us to make sense of the large and everincreasing body of medical knowledge, it has also led us, whether consciously or not, to separate the socalled 'mind' problems and the 'body' problems in our clinical practice, ignoring their inter-relationship.

It is now a common tendency to classify illnesses into those that we think have a physical or organic cause and those, which we consider to be psychological or psychosomatic or non-organic in origin. This is undoubtedly convenient for the busy clinician but there is increasing awareness that such clear-cut division of diseases into 'physical' (body) and 'psychological' (mind) categories is an oversimplification and often wrong. We are beginning to recognise that all diseases, even genetic diseases and congenital malformations, have both physical and psychological elements that we cannot ignore. The mind and the body may appear separate, but they are, in fact, unified.

When patients discover they have serious illnesses, the accompanying shock has major effects on their mental and emotional states. Illness affects how one feels in many ways, often causing one to plunge into the depths of depression. In the case of children, their selfimage and development can also be affected. In many instances, the impact upon their young minds can have lasting consequences.

The mind can also affect the body. It is well recognised that symptoms of 'physical' diseases such as peptic ulcer disease can worsen in times of stress. Severe 
emotional turmoil can precipitate a cardiac arrest. Great joy as well as deep sorrow lead one to shed tears. Expressions in the English language such as 'trembling with fear', 'the heart beating in excitement' and 'shaking with laughter' show that even long ago, people have recognised the influence of emotions on the body. One's emotional state is revealed in one's physical appearance and attributes of the mind such as confidence is reflected in the quality of one's voice.

\section{Functional gastrointestinal symptoms in children}

There are a large number of children with severe physical complaints - such as headache, abdominal pain and vomiting - without any detectable physical cause. The pain experienced by these patients is real, and often, very severe and yet, conventional tests could not reveal any pathology.

A survey of elementary school-children in Malaysia revealed that about ten percent of them suffered from the syndrome of recurrent abdominal pain, defined as at least three episodes of stomach-aches intense enough to interfere with their daily lives over a period of at least three months (3). Among Malaysian children with recurrent abdominal pain who were admitted to hospital, a significant proportion of over $95 \%$ were found not to have detectable abnormalities that could account for the symptom, whether on physical examination or investigation (4).

The presence of organic pathology does not necessarily imply that it is the cause of a patient's symptoms. For example, the organism Helicobacter pylori was once proposed to be an important cause of childhood recurrent abdominal pain. However, analyses of various paediatric studies suggest that there is insufficient evidence to support this proposal (5). In a study on $H$. pylori sero-positivity, a relatively high prevalence of $H$. pylori (16.7\%) was noted in asymptomatic Malaysian teenagers, indicating that the organism could be present without causing symptoms (6). Furthermore, the prevalence of $H$. pylori sero-positivity among asymptomatic Malaysian children was lowest in Malays (6.6\%), intermediate in Chinese (10.4\%) and highest in Indians (17.9\%) (6). Interestingly, this was the opposite of the prevalence pattern of recurrent abdominal pain found in the same population where recurrent abdominal pain was most common in the Malays
(11.9\%), intermediate in the Chinese (9.3\%) and least common in the Indians (8.2\%) (7).

Current research shows that childhood recurrent abdominal pain is multi-factorial in origin with a major psycho-social component. For instance, a strong correlation has been found between stressful life-events and the occurrence of recurrent abdominal pain in both rural and urban schoolchildren aged between nine and fifteen years $(8,9,10)$. The life-events included the loss of a family member through death, the change in occupation of a family member, hospitalisation of a family member, the child's own hospitalisation, recent change of address, change in occupation of an immediate family member, failure in a major school examination and bullying at school. Stressful life-events was not only associated with increased complaints of physical symptoms, but was also linked to poor academic performance (11). What is worrying is that children with recurrent abdominal pain often miss school on account of their symptoms, with studies showing that at least a third of these children missed more than two weeks of school over a six-month period (7).

Another condition frequently seen is the syndrome of cyclical vomiting, which is a condition characterised by recurrent stereotypical bouts of vomiting with intervening periods of normal health and the absence of an organic cause. Many of these patients have some kind of psychosocial precipitating factor.

The following case of a ten-year-old boy with recurrent vomiting illustrates the problem. He was the only child of well-educated parents. The child's episodes of vomiting occurred several times a year and were often severe, resulting in electrolyte disturbances. Hospital investigations did not reveal any organic cause for the symptoms. There were no obvious precipitating factors at first. However, a more detailed history revealed that there was a feeling of guilt in the family originating in the grandfather and transmitted also to his father. The grandfather was a soldier who had killed during war and unresolved feelings of profound guilt led him to commit suicide a number of years ago. The family did not discuss this matter openly. However, it was a severe shock to the sensitive young boy and suppressing it all was likely to be an important cause of his symptoms. Once this possibility was recognised and the whole family was 
encouraged to talk about it, the episodes of vomiting started to reduce significantly.

The above studies and case report show that issues of the mind cannot be separated from those of the body. It is essential not to just look at the physical aspect alone, even though it may appear that the patient - whether adult or child - is only complaining of a physical symptom such as "abdominal pain" and "headache" or diagnosed with a so-called "physical disease" like "asthma" and "diabetes". It is important to know what the patient and, indeed, the family are thinking about and feeling - otherwise the management of the patient is incomplete. A doctor needs to pay attention to more than a diseased organ, more even than the whole man - it is crucial that he considers the man in his world.

An important obligation of adults today is to create the conditions in the family, the school and in society for children to grow up happily with healthy bodies and minds. Symptoms such as stomach-aches and vomiting can often be a child's subconscious cry for help. Giving adequate time to the child and listening with concern to whatever he or she has to say is essential if we wish to understand the world of our children and help them. Parents and teachers who do not realize this point exacerbate the problem and end up putting further pressure on the child. This can lead to chronic illness.

\section{The body's reaction to psychosocial stress and depression}

One of the areas where mind-body interactions has been studied is the effects of mental conditions such as depression and stress on the body. 'Stress' can be described as a condition that affects people when the demands made on them exceed their capacity to meet those demands (12). A number of papers have shown that there is association between depression and stress on the one hand and diseases traditionally thought to be 'physical' or organic diseases on the other.

Depression was found to coexist with Crohn disease more often than would be expected by chance $(13,14)$. It is unclear whether depression occurred as a result of the disease, or whether depression played a role in facilitating the expression of the inflammatory bowel disease. Depression has also been found to increase mortality and morbidity in patients with heart failure. Such adverse associations persist after adjustment for conventional prognostic risk factors (15).

It is not entirely clear what the mechanisms are that account for the observed association between various diseases and depression or stress. In recent years, there have been various studies that attempt to look at possible mechanisms, although, we still do not have a completely satisfactory explanation. For instance, depression has been found to be associated with inflammation as evidenced by the finding of increased levels of C-reactive protein (16). Increased TNF-alpha levels and coagulation factors have also been shown to be present in depression $(17,18)$. Animal studies show that mice subjected to maternal deprivation develop a behavioural pattern reminiscent of depression and are more susceptible to inflammation (19).

It has also been proposed that another possible mechanism linking depression with disorders such as cardiac pathology is autonomic imbalance. Some of the abnormalities that have been found include impaired parasympathomimetic functions and a dominant sympathetic drive $(20,21)$.

Whatever the mechanisms may be, mental or psychological stress has been linked to a variety of other conditions such as skin disorders, allergies, asthma and even malignancy. Depression and hopelessness seem to reduce the body's resistance, making one vulnerable to various illnesses. Further studies are needed to obtain more evidence but what is available, so far, seems to support the concept that mind and body are inseparable.

\section{The effect of a positive mind-set on the body}

While there have been some studies on the negative effects of stress and depression on the body, even less is known about the effect of a positive mind-set. It seems reasonable, however, to propose that a positive mind-set should also have positive effects on the body. What are the effects of positive psychological events on the body? We are still in the early stages of understanding and there are not many studies that test and document this possibility. There are, however, many anecdotal reports from reputable sources and it would be unwise to disregard them. 
Using again the example of Crohn disease quoted earlier, my own unpublished experience suggests that there are some patients with a severe form of the disease who have better outcome than others with less severe physical disease but who are anxious, tense and withdrawn. These patients are usually positive individuals, who do not let their illness limit their functioning, participating in a wide range of academic and extracurricular activities.

The late Dr. Norman Cousins (1915-1990), formerly an adjunct professor at the School of Medicine, University of California, Los Angeles (UCLA), wrote in an article published in 1976 in the New England Journal of Medicine as follows:

"The will to live is not a theoretical abstraction but a physiologic reality with therapeutic characteristics...I have learned never to underestimate the capacity of the human mind and body to regenerate - even when the prospects seem most wretched. The lifeforce may be the least understood force on earth.... Human beings tend to live too far within self-imposed limits. It is possible that these limits will recede when we respect more fully the natural drive of the human mind and body toward perfectibility and regeneration. Protecting and cherishing that natural drive may well represent the finest exercise of human freedom" (22).

What was it that led Dr. Cousins to make such a comment? In the 1920s, when Dr Cousins himself was diagnosed with tuberculosis, he was sent away to a sanatorium where he noticed that although two patients might have similar medical conditions, the one who was hopeful and optimistic was far more likely to actually recover. Years later, he himself survived a life-threatening connective-tissue disease at the age of 50 and recovered from cardiac infarction at the age of 65 . While cooperating fully with his physicians, Dr Cousins also realised that a crucial factor in his recovery was his own powerful determination to beat his illness. He, subsequently, became convinced that a positive determination to overcome illness could actually stimulate our organs and even individual cells towards health.

Exactly one hundred years ago, in 1910, Dr. William Osler, Regius Professor of Medicine at Oxford University made a similar observation in the British Medical Journal.
"Nothing in life is more wonderful than faith - the one great moving force which we can neither weigh in the balance nor test in the crucible. Intangible as the ether, ineluctable as gravitation, the radium of the moral and mental spheres, mysterious, indefinable, known only by its effects, faith pours out an unfailing stream of energy..." (23).

\section{The importance of giving patients the courage not to be defeated by their illness}

What is the practical clinical implication of knowing that there is close interaction between mind and body?

Based on his experience, Dr. Cousins stated, as follows: "One of the doctor's biggest jobs is to encourage to the fullest the patient's will to live and to mobilize all the natural resources of body and mind to combat disease" $(22,24,25)$.

$S$ is a patient who is now in her twenties. She had biliary atresia and had a Kasai operation. Although the operation managed to overcome biliary obstruction and re-establish bile flow, her liver had already been damaged before surgery and she needed constant follow-up and surveillance. About five years previously, her mother, who had been her pillar of support, died from breast cancer. Her bereavement, together with her own chronic illness, caused her to fall into the depths of depression and she lost the will to live. However, with constant encouragement from her father as well as the medical and nursing staff, she managed not only to live on but also developed the courage to pursue tertiary education.

When one of her doctors saw her, she told him with pride that she had completed her university thesis on the activities of young women during the Second World War. It was an academic thesis but at the same time, it was full of feelings of sympathy for the plight of war victims. Her sensitivity was, no doubt, sharpened by the fact that she had undergone illness and bereavement herself. She had managed to turn her own misfortune into something very positive.

This experience illustrates that illnesses can serve to nourish one's heart. A person who accepts his illness positively and perseveres through it will achieve greater depth and strength as a human being. 
It also serves to remind health care professionals of the importance of providing constant warm encouragement to their patients in addition to dealing with the actual disease itself. Encouragement does not simply mean unreasonably telling the patient that an illness can be cured completely. It means not giving up on the patient as a human being even when the disease cannot be cured. This experience emphasises the importance of encouraging patients to develop the strength of mind that enables the patient to rise above an illness and achieve great satisfaction despite the disease still being present.

\section{Lessons from the life of Helen Keller}

The positive interaction between mind and body is well-illustrated in the lives of many people, some wellknown while others, less so. They all demonstrate the fact that the severity of a physical handicap varies according to the person's emotional reaction to it. Blindness and deafness, for example, may seem to be completely physical problems. However, does the handicap result in loss of hope or does it become a challenge to be overcome? Helen Keller was a shining example of someone who had attained great heights despite being physically handicapped.

Helen Keller was born in Alabama in 1880. At the age of nineteen months, she was afflicted by an acute lifethreatening illness that eventually left her blind and deaf. The years that followed were hellish for her family. There was no way to communicate with the young child. Imprisoned in her body, lonely in a silent world and unable to tell others her feelings and wishes, Helen would often rage about like a wild animal.

Helen's life was transformed when she met her teacher, Anne Sullivan, who was herself partially blind. There was a significant moment when Helen first realised that things around her had names. It was the moment when Ann Sullivan placed one of Helen's hands in a stream of water and then spelled the word water into her other palm.

Helen described her feelings at that moment in her autobiography, The Story of My Life:

"I stood still, my whole attention fixed upon the motions of her fingers. Suddenly, I felt a misty consciousness as of something forgotten - a thrill of returning thought; and somehow the mystery of language was revealed to me. I knew then that ' $w$-a-t-e-r' meant that wonderful cool something that was flowing over my hand. That living word awakened my soul, gave it light, hope, joy, set it free! There were barriers still, it is true, but barriers that could in time be swept away" (26).

From that moment onwards, Helen continued to make astounding progress. She eventually graduated from college and dedicated herself to helping the blind and handicapped.

Helen Keller's story is a testimony to the powerful interaction between mind and body, and shows that the remarkable potential latent within the life of a single determined individual need not be held back by physical disability. Conversely, even if someone has great physical strength, but lacks a resolute spirit, he cannot reach the full potential of full play to his abilities.

Helen's story also contains an important lesson for health-care professionals. Her moment of breakthrough, related above, is now well-known but it was actually only possible because of something less well-known but equally important - Ann Sullivan's patience and her belief in Helen's potential. Helen had initially rejected any contact with Ann Sullivan, but as a result of Sullivan's painstaking effort to reach out to Helen, a warm and solid relationship of trust was forged which enabled the break-through to occur. Doctors, nurses, teachers and indeed everyone who has the responsibility to care for a patient, have much to learn from the courageous example shown by Ann Sullivan.

\section{Strength of the mind in the face of terminal illness}

Terminal care is an area where careful consideration of the mind is of great importance but sadly, often forgotten.

T was an eleven-year old girl who died of leukaemia a few years ago in the University of Malaya Medical Centre. Coming from another part of Malaysia, it was not easy for her to adapt to life in Kuala Lumpur while having to come to terms with the reality of her diagnosis. In the beginning, she fell into depression and shut herself up from other people. Over the 
subsequent months, however, she developed a great realisation. She realised that the quality and significance of one's life is not necessarily dependent only on its length, but increases in proportion to the depth in which one lives one's life and the value one creates. It was a remarkably profound and mature realisation for any person, let alone for a child of her age. Young children, especially sick ones, often have thoughts that are more profound than we can ever imagine.

During the last year of her short life, she was determined to do something useful with her life. She decided to challenge herself to do well in her primary school examinations. Although her illness resulted in her missing a lot of school, her determination was strong and she gave everything she had to her studies.

As Helen Keller once said, "When we do the best that we can, we never know what miracle is wrought in our life, or in the life of another". T's parents and many friends around her age were greatly moved and encouraged when she managed to obtain four distinctions in the examination, in spite of her illness. It was not the examination result itself that was most important but rather it was the tenacity of her spirit and the determination not to be defeated by her illness that really moved others.

Just before she died, she expressed a wish to attend university. Although some may call her unrealistic, one cannot help but marvel at the resilience and positivity of her spirit. T eventually grew weaker and, finally, passed away. Although weak and diseased, she had a peaceful countenance at death. One's appearance at death is a good indicator of one's state of mind.

At a time when a disease is incurable, it is easy for both patient and doctor to harbour feelings of futility and uselessness. There is also a temptation to carry out desperate, heroic acts. There is much for both doctors and nurses to learn from the courageous attitude of this young patient in facing death. This experience shows how important it is for care-givers to be sensitive and to carefully consider a patient's state of mind in the final moments of life. It is a grave mistake to separate the mind from the body and consider only the physical disease. This can lead to treatment being administered to terminally-ill patients excessively and unreasonably, thereby causing more pain and anguish. Such an attitude also leads to despair and loss of hope for both the terminally ill patient and care-giver when all medical treatment is futile.

There is an important difference between the courage to look the truth in the face, accepting the fact that all living things must die while creating value out of the remaining days of life, and the typically arrogant pathological view that life and death should be subject to our will, desire and control.

\section{Conclusion - Looking towards the future}

Evidence, both laboratory and clinical, is accumulating that the mind and the body interact very closely. Concepts concerning the relationship between mind and body are moving from dualism to inseparability. True health must include both the physical body and the mind.

With regard to children's health, this article emphasizes that an important obligation of adults today is to create the conditions in the family, the school and in society for children to grow up happily with healthy bodies and minds. Giving adequate time to the child and listening with concern to whatever he or she has to say, is essential if we wish to understand the world of our children and help them.

One of the most important implications of our understanding of the interaction between the mind and body is an appreciation of the tremendous potential that exists in the life of each individual. We have seen examples that the strength of the heart or mind is an important key to release this energy. Therefore, in addition to offering the best of medical and surgical therapy, it is essential to fully engage the patients' own ability to mobilize the forces of mind and body in their battle against illnesses. With regard to this, it is the bond of trust between care-giverand patient, between one human being and another, that most of all, can help the patient to strengthen the power of the mind.

To ensure that future generations of doctors, nurses and other health-care professionals realize the full significance of these points and appreciate the dignity of life is one of the most important tasks of a medical school. Dr. Norman Cousins once emphasised that one of the biggest needs in medical education today is to 
attract students who are well-rounded human beings; who will be interested in people and not just in the diseases that affect them; who can comprehend the reality of suffering and not just its symptoms; whose prescription pad will not exclude the human touch. In essence, what is needed is a profound reverence for the dignity of life as expressed poetically in the following words by Dr. Daisaku Ikeda:

There is something vaster than the wide open skyand that is, my life There is something deeper than the fathomless seaand that is, your life.

There is something more precious than all the treasures of the universeand that is, our lives (27).

(This article is based on an inaugural lecture delivered on 26th May 2009 at the University of Malaya)

\section{References}

1. Hippocrates. Tradition in Medicine. In: Hippocratic Writings. Ed. GER Lloyd. Middlesex, England: Penguin; 1983.

2. Unger, F, Ikeda D. A Dialogue - Compassion and Tolerance. J Orient Studi 2005; 15: 8-9.

3. Boey CCM, Yap SB. The prevalence of recurrent abdominal pain in eleven to sixteen-year old Malaysian school-children. J Paediatr Child Health 2000; 36: 114-116.

4. Boey CCM , Goh KL, Hassal E, Magid M. Endoscopy in children with recurrent abdominal pain. Gastrointest Endosc. 2001; 53:142-143.

5. Sherman PM, Macarthur C. Current controversies with Helicobacter pylori infection in the pediatric population. Front Biosci 2001; 6: E187-192.

6. Boey CCM, Goh KL, Lee WS, Parasakthi N. Seroprevalence of Helicobacter pylori infection in Malaysian children: Evidence for ethnic differences in childhood. J Paediatr Child Health 1999; 35(2): 151-152.
7. Boey CCM. Recurrent Abdominal Pain in Malaysian Children. (MD Thesis). Kuala Lumpur: University of Malaya, 2000.

8. Boey CCM, Goh KL. Stressful life events and recurrent abdominal pain in children in a rural district in Malaysia. Eur J of Gastroenterol Hepatol 2001; 13: 401-404.

9. Boey CCM, Goh KL. The significance of life-events as contributing factors in childhood recurrent abdominal pain in an urban community in Malaysia. J Psychosom Research 2001; 51(4): 559562.

10. Boey CCM. Somatization and recurrent abdominal pain. In: Pediatric Gastroenterology 2004. Reports from the 2nd World Congress of Pediatric Gastroenterology, Hepatology and Nutrition (Paris, France July 3-7, 2004). Medimond, Bologna, Italy; 319-325.

11. Boey CCM, Omar A, Phillips JA. Correlation among academic performance, recurrent abdominal pain and other factors in year 6 urban primary school children in Malaysia. J Paediatr Child Health 2003; 39(5): 352-357.

12. Kaplan, Sadock. Synopsis of Psychiatry: Behavioral Sciences/Clinical Psychiatry. 8th Edition. Lippincott: Williams \& Wilkins; 1998.

13. Gerbert B. Psychological Aspects of Crohn's Disease. J Behav Med 1980 Mar; 3(1): 41-58.

14. North CS, Alpers DH. A review of studies of psychiatric factors in Crohn's disease: etiologic implications. Ann Clin Psychiatry 1994 Jun; 6(2): 117-124.

15. Jiang W, Krishnan, RR; O'Connor CM. Depression and heart disease: evidence of a link, and its therapeutic implications. CNS Drugs 2002;16: 111127.

16. Ford, DE, Erlinger TP. Depression and C-reactive protein in US adults: data from the Third National Health and Nutrition Examination Survey. Arch Intern Med 2004;164:1010-1014.

17. Tuglu C, Kara SH, Caliyurt O, Vardar E, Abay E. Increased serum tumor necrosis factoralpha levels and treatment response in major 
depressive disorder. Psychopharmacology (Berl.) 2003; 170: 429-433.

18. Panagiotakos DB, et al. Inflammation, coagulation, and depressive symptomatology in cardiovascular disease-free people; the ATTICA study. Eur Heart $J$ 2004; 25: 492-499.

19. Varghese AK, et al. Antidepressants attenuate increased susceptibility to colitis in a murine model of depression. Gastroenterology 2006; 130: 1743-1753.

20. Nahas $Z$, et al. Serial vagus nerve stimulation functional MRI in treatment-resistant depression. Neuropsychopharmacology 2007; 32: 1649-1660.

21. Gorman JM, Sloan RP. Heart rate variability in depressive and anxiety disorders. Am Heart J 2000; 140(4 Suppl): 77-83.
22. Cousins N. Anatomy of an Illness as Perceived by the Patient. New Engl J Med 1976; 295: 1458-1463 .

23. Osler W. The Faith that Heals. Br Med J 1910 June 18; 1(2581): 1470-1472.

24. Cousins N. Anatomy of an Illness as Perceived by the Patient, Reflections on Healing and Regeneration. NY: Bantam Books; 1981.

25. Cousins N. Healing and Belief, Human Options. NY: WW Norton; 1981.

26. Keller H. The Story of My Life. NY: Bantam Books; 1990.

27. Ikeda D. Peace-The Foundation for Lasting Human Happiness (a poem). SGI Newsletter (2007): 7234. 